\title{
CORRIGENDUM
}

\section{Inhibition of LNCaP prostate tumor growth in vivo by an antisense oligonucleotide directed against the human androgen receptor}

\author{
IE Eder, J Hoffmann, H Rogatsch, G Schäfer, D Zopf, G Bartsch and H Klocker
}

Cancer Gene Therapy (2007) 14, 934; doi:10.1038/sj.cgt.7701085

Correction to: Cancer Gene Therapy (2002) 9, 117-125; doi:10.1038/sj.cgt.7700416

The authors have noticed an error in the 'Materials and methods' section, where the sequence of the antisense ODNas750/15 targeting the $\mathrm{N}$-terminal polyglutamine encoding CAG triplet repeat region was published incorrectly.

The correct sequence is shown below:

$5^{\prime}$-CTGCTGCTGCTGCTG-3' instead of 5'-GTCGTC GTCGTCGTC-3'.

The authors would like to apologize for this mistake. 